* Advogada. Professora Convidada no Curso de Especialização em Direito e Processo Penal da Universidade Presbiteriana Mackenzie. Professora da Disciplina de Metodologia e Didática para os cursos de Pós graduação das Faculdades Metropolitanas Unidas. Possui graduação em Direito pela Universidade Presbiteriana Mackenzie, em 2008. Mestre em Direito Político e Econômico, pela Universidade Presbiteriana Mackenzie em 2012. Especialista em Direito Empresarial (2010), pela mesma Universidade. Realiza pesquisas nos grupos "Políticas Públicas como instrumento de efetivação da Cidadania" e "Novos Direitos e proteção da cidadania: evolução normativa, doutrinária e jurisprudencial", que são vinculados ao Programa de Pós-Graduação Stricto Sensu da Faculdade de Direito da Universidade Mackenzie. E-mail: mariafernanda_soares macedo@yahoo.com.br

\section{Alterações climáticas e o direito internacional dos refugiados: a busca pela dignidade humana e pela cidadania dos refugiados ambientais}

\author{
Climate Change AND THE INTERNATIONAL \\ REFUGEE LAW: THE SEARCH FOR HUMAN DIGNITY \\ AND CITIZENSHIP OF ENVIRONMENTAL REFUGEES
}

* Maria Fernanda Soares Macedo

Resumo: Apresenta a importância do reconhecimento da condição jurídica de refugiados ambientais para as pessoas que são obrigadas a saírem de seus lares e se deslocarem para outros países em decorrência de catástrofes naturais ou condições climáticas desfavoráveis. Tendo em vista que milhares de pessoas tiveram e tem que deixar os seus países, para poderem sobreviver, são fundamentais políticas públicas e legislações específicas para que elas sejam acolhidas em seus novos destinos, que tenham suporte médico, assistencial, psicológico, jurídico e educacional, e que a elas sejam garantidas a dignidade humana e a cidadania, e os direitos destas decorrentes. O tema é complexo e não se pretende esgotá-lo. Envolve diversas ramificações do Direito, com ênfase para os Direitos Humanos, o Direito Ambiental, o Direito Constitucional e o Direito Internacional.

Palavras-chave: Refugiados ambientais; Mudanças climáticas; Cidadania; Dignidade humana.

Abstract: This article intends to present the importance of recognizing the legal status of environmental refugees for people who are obligated to leave their homes and move to other countries because of natural disasters. In view of thousands of people, victims of environmental disasters had to leave their countries, in order to survive, are fundamental public policies and specific laws that these people are up in their new destinations that have medical care, psychological, legal support and educational, and that they are guaranteed human dignity and citizenship, and the rights of these arising. The subject is complex (precisely for this reason will not be exhausted in this text), and involves several branches of law, with emphasis on human rights, environmental law, constitutional law and international law.

Keywords: Environmental refugees; Climate change; Citizenship; Human dignity. 
É hora de reconhecer que estamos enfrentando nada menos do que um novo paradigma do conceito de deslocamento no século XXI, com uma infinidade de fatores impulsionadores que levam as pessoas a deixar seus lares a uma escala sem precedentes. Alto Comissário das Nações Unidas para refugiados, António Guterres em 20 de Junho de 2007. (ALTO COMISSARIADO DAS NAÇÕES UNIDAS PARAREFUGIADOS, 2014a).

\section{INTRODUÇÃO}

O Planeta Terra é composto por quatro camadas principais: crosta, manto, núcleo externo e núcleo interno, cada uma possuindo as suas peculiaridades e funções, e pelos ecossistemas: terrestre, atmosférico e aquático. $\mathrm{O}$ equilíbrio entre eles permite e garante a sobrevivência e perpetuação dos seres humanos, da flora e da fauna. (BRASIL, 2011).

Crosta da Terra: é a camada sólida sobre a qual vivemos. Ela varia consideravelmente em espessura, sendo mais fina sob os oceanos e mais espessa nas regiões onde forma os continentes. Sua espessura varia de 5 a $40 \mathrm{Km}$. Manto da Terra: é a camada que vem logo abaixo da crosta. A maior parte da massa da Terra está localizada no manto. O manto não é sólido. Região central da Terra: é dividida em duas partes - região central externa e região central interna. Região central externa: é formada por ferro, níquel e alguns elementos mais leves. Região central interna: é aí que se encontra o verdadeiro centro da Terra. Essa região é sólida e vai de $5150 \mathrm{Km}$ de profundidade a $6378 \mathrm{Km}$, onde está o centro de nosso planeta. Alguns cientistas acham que essa região é formada por um corpo único de ferro, mas outros acreditam que sua parte mais interna contém ouro, platina e outros elementos. (BRASIL, 2011).

Mudanças climáticas sempre aconteceram em nosso Planeta. Entretanto, a partir da Revolução Industrial ${ }^{1}$, observa-se a aceleração destas, justamente

\footnotetext{
${ }^{1}$ Período marcado pela transição da manufatura para a produção em larga escala. Neste processo, a manufatura foi substituída pelas máquinas, o aumento do uso do ferro, da energia e do carvão. A Revolução Industrial é dividida didaticamente nas seguintes fases: Primeira: ocorrida entre 1760 e 1860, abrange inicialmente apenas a Inglaterra. Neste período surgem as indústrias de tecidos de algodão, e os trabalhadores utilizam o tear mecânico. O contínuo desenvolvimento das máquinas a vapor permitiu a continuidade da Revolução. Segunda: período entre 1860 e 1900. Verifica-se o alastramento da Revolução Industrial, especialmente na Alemanha, na França e na Itália. Esta fase foi marcada por grandes inovações tais quais: o uso do aço, da energia elétrica, a criação do motor a explosão (o que permite a aceleração da produção de bens), além do desenvolvimento e da utilização de produtos químicos. Terceira: período entre os séculos XX e XXI, marcado pelas inovações tecnológicas e revolucionárias na área da informática (como os computadores), primeiramente destinadas ao Governo e às empresas e depois com o acesso ampliado para os particulares, além da utilização de novas fontes de energia como, por exemplo, a nuclear.
} 
por conta das ações dos homens, cada vez mais intensificadas. Atividades como a agricultura, a agropecuária, a pesca, a busca pelo petróleo, bem como a automação e as produções em larga escala são muito importantes para a economia, para a geração e manutenção de empregos, porém, se desenvolvidas sem planejamento e cuidado, afetam diretamente o equilíbrio ecológico. Outras situações que também danificam o meio ambiente são as queimadas de vegetação, queima de combustíveis fósseis, derrubadas de florestas e poluiçõos aéreas, terrestres, fluviais e marítimas, que geram o desmatamento, a poluição e o aquecimento global ${ }^{2}$ (causado pela intensificação do efeito estufa, que ocorre em decorrência do excesso da concentração de determinados gases na atmosfera, como o dióxido de carbono, o metano e o óxido nitroso), proporcionando uma série de fenômenos climáticos que, por muitas vezes, são altamente devastadores, impactando diretamente no clima, na fauna e vegetação locais, bem como na vida dos moradores da região.

Alguns exemplos de tais fenômenos são os terremotos, maremotos, tempestades, enchentes e vendavais. O sofrimento das pessoas sobreviventes atingidas pelos desastres é intenso ${ }^{3}$, e, de maneira imediata, agravado pela falta de estrutura pública e privada para lidar com a situação emergencial ${ }^{4}$.

De maneira mediata, as dificuldades permanecem: obras públicas e privadas são destruídas, a economia é prejudicada e a impossibilidade de permanecerem no local os faz buscar novos países para poderem sobreviver. O deslocamento (que pode ser temporário ou permanente) e chegada ao novo local apresentam uma série de riscos e dificuldades, tais quais: a dificuldade de comunicação pelo não domínio da língua, empecilhos burocráticos, problemas de ordem econômica, falta de informações, falta de abrigos, de tratamentos, de assistência médico-hospitalar, psicológica, a falta

\footnotetext{
2 Sobre o tema "aquecimento global", recomenda-se o filme "Uma Verdade Inconveniente: o que devemos fazer (e saber) sobre o aquecimento global" (lançado em 03 de novembro de 2006), dirigido por Davis Guggenheim e apresentado pelo ambientalista Gore Junior. O enredo trata do aquecimento global e suas consequências devastadoras. O documentário tem caráter informativo e educativo, mostrando a gravidade da situação e medidas importantes para a preservação ambiental como forma de combate aos desastres climáticos ambientais.

${ }^{3}$ Este assunto será aprofundado no Tópico 1: Alterações climáticas, dignidade humana e as dificuldades enfrentadas pelos refugiados ambientais.

${ }^{4}$ Especialmente com a falta de saneamento, de leitos para que todas as vítimas sejam amparadas, a falta de medicamentos, de médicos, enfermeiros, psicólogos, a impossibilidade de esterilização das roupas utilizadas em hospitais e instrumentos hospitalares de maneira adequada, o que pode desencadear epidemias. Existe também a possibilidade destas pessoas serem picadas por animais peçonhentos, escondidos nos destroços. A situação é agravada pela falta de água potável, de energia elétrica, de alimentos, abrigos e roupas e pelas condições climáticas: chuvas, frio ou calor excessivos.
} 
de oportunidades de emprego e de estudo, o que impede uma série de direitos e garantias.

Outra situação pode ocorrer. Ao invés do deslocamento em decorrência de uma catástrofe climática, as pessoas saem dos lugares em que moram em busca de refúgio porque lentamente a alteração climática foi transformando o lugar, tornando inviável (ou muito difícil) a habitação e compromete a sobrevivência. É o caso, por exemplo, da expansão do deserto na África subsaariana, especialmente nos países do Sahel, o que causa o deslocamento de milhões de pessoas, principalmente para o sul ou para a África do Norte ${ }^{5}$. (BROWN, 2009).

Lester Brown (2009) aponta a Itália como um dos países que refugiados africanos estavam tentando chegar, e algumas das dificuldades por eles enfrentadas no trajeto:

Em meados de outubro de 2003, as autoridades da Itália descobriram um barco que se dirigia a esse país transportando refugiados procedentes da África. A embarcação esteve à deriva mais de duas semanas, ficou sem combustível, alimentos e água. Muitos dos passageiros morreram. No começo, os cadáveres foram jogados na água. Mas, após algum tempo, os sobreviventes ficaram sem forças para levantar os corpos. Deste modo, vivos e mortos compartilharam o bote. Um socorrista descreveu o que viu como "uma cena do inferno de "Dante Alighieri." (BROWN, 2009).

\section{ALTERAÇÕES CLIMÁTICAS, DIGNIDADE HUMANA E AS DIFICULDADES ENFRENTADAS PELOS REFUGIADOS AMBIENTAIS}

Estabelece o art. $1^{\text {a }}$ da Declaração Universal dos Direitos do Homem e do Cidadão de 1948: "Todos os seres humanos nascem livres e iguais em dignidade e direitos. São dotados de razão e consciência e devem agir em relação uns aos outros com espírito de fraternidade". (BRASIL, 2009).

O art. inaugural da Constituição Federal Brasileira de 1988 prevê:

Art. $1^{\circ}$ A República Federativa do Brasil, formada pela união indissolúvel dos Estados e Municípios e do Distrito Federal, constitui-se em Estado Democrático de Direito e tem como fundamentos: I - a soberania; II - a cidadania

\footnotetext{
${ }^{5}$ Washington, 23 de outubro de 2009.
} 
III - a dignidade da pessoa humana; IV - os valores sociais do trabalho e da livre iniciativa; V - o pluralismo político. Parágrafo único. Todo o poder emana do povo, que o exerce por meio de representantes eleitos ou diretamente, nos termos desta Constituição. (BRASIL, 1988).

Não é por acaso que a dignidade humana está prevista nos artigos iniciais de tão importantes legislações: esta deve ser o vetor principal das legislações, para a garantia da vida, da proteção humana, e o parâmetro para todas as outras normas. A dignidade humana deve ser absolutamente, integralmente e universalmente garantida e respeitada. Nos dizeres de Ingo Sarlet (2009, p. 67):

A dignidade humana é a qualidade intrínseca e distintiva reconhecida em cada ser humano que o faz merecedor do mesmo respeito e consideração por parte do Estado e da comunidade, implicando, neste sentido, um complexo de direitos e deveres fundamentais que assegurem a pessoa tanto contra todo e qualquer ato de cunho degradante e desumano, como venham a lhe garantir as condições existenciais mínimas para uma vida saudável, além de propiciar e promover sua participação ativa e corresponsável nos destinos da própria existência e da vida em comunhão com os demais seres humanos, mediante o devido respeito aos demais seres que integram a rede da vida.

Entretanto, é necessário destacar que os refugiados ambientais vivenciam inúmeras dificuldades: no momento do desastre ambiental (ou antes deste, ao longo do tempo, com as alterações climáticas), em período posterior, mas ainda em seu país, no deslocamento e ao chegarem em seus novos destinos. Por não serem enquadrados no conceito de refugiados da Convenção das Nações Unidas sobre o Estatuto dos Refugiados de 28 de julho de $1951^{6}$, isto lhes suprime uma série de direitos e garantias, situação esta que afeta diretamente os direitos humanos, a dignidade humana e a cidadania. Celso Lafer (1997, p. 58), baseandose nas lições de Hannah Arendt, explica que:

A experiência histórica dos displaced people levou Hannah Arendt a concluir que a cidadania ${ }^{8}$ é o direito a ter direitos, pois a igualdade em dignidade e direito dos seres humanos não é um dado. É um construído da

\footnotetext{
${ }^{6}$ Este tópico será aprofundado no presente artigo em momento oportuno.

7 Refugiados. O termo "displaced people", que foi muito utilizado na Segunda Guerra, é também identificado pela sigla "DP".

8 A cidadania deve ser universalmente garantida.
} 
convivência coletiva, que requer o acesso a um espaço público comum. Em resumo, é esse acesso ao espaço público - o direito de pertencer a uma comunidade política - que permite a construção de um mundo comum através do processo de asserção dos direitos humanos.

Gianpaolo Poggio Smanio (2013, p. 12-13) leciona sobre o tema, relacionando-o com o direito brasileiro:

A Constituição Federal de 1988, chamada de "Constituição-cidadã", efetivou uma mudança na conceituação de cidadania, conferindo maior amplitude ao seu significado, ao colocá-la dentre os princípios fundamentais da República Federativa do Brasil (art. $1^{\circ}$, II). A cidadania deixou de estar relacionada apenas com a nacionalidade, deixou de ser considerada apenas um status de reconhecimento do Estado, para ser um conceito amplo, compatível com uma nova dimensão da cidadania, como expressão de direitos fundamentais e de solidariedade.

Conforme análise de Hannah Arendt (2009, p. 330), o primeiro dos direitos do homem é o "direito a ter direitos, o que implica na dimensão e o conceito de cidadania como um meio para a proteção de direitos e também como um princípio, pois a destituição da cidadania implica na perda desses direitos."

Dentre os desastres naturais, lembremos do Tsunami que ocorreu em 26 de dezembro de 2004 no oceano índico com a formação de ondas gigantes que deixou um rastro de destruição em 14 países, e o furação Katrina, que teve seu pico em 28 de agosto de 2005 em Nova Orleans, e atingiu o grau 5 da Escala de Furacões de Saffir-Simpson.

Sobre a classificação da Escala de Furações:

A escala Saffir-Simpson vai de 1 a 5 e mede a intensidade dos ventos dos furacões, classificados por categorias. Foi criada em 1969 pelo engenheiro civil Herbert Saffir e pelo meteorologista Robert Simpson. A escala SaffirSimpson é usada para dar a estimativa do potencial risco de danos e inundações esperados durante a passagem de um furacão. A categoria é estimada através da velocidade do vento mantida durante 1 minuto, daí a expressão "ventos sustentados", quando referem-se a furacões.

Categoria 1: Ventos entre 119 e $153 \mathrm{~km} / \mathrm{h}$. As ondas provocadas pela tempestade aumentam entre 1,3 e 1,5 metros acima de seu nível normal. Não há riscos reais nas estruturas. Porém há riscos menores para trailers soltos e queda de pequenas árvores. Alguns outdoors mal construídos podem ser arrancados. Também alguns alagamentos podem ser ocorrer próximos à costa, 
assim como alguns desmoronamentos.

Categoria 2: Ventos entre 154 e $177 \mathrm{~km} / \mathrm{h}$. As ondas atingem uma altura entre 1,8 e 2,45 metros acima de seu nível normal. Causa danos em telhados, janelas e portas, podendo também arrancá-los. Danos consideráveis em árvores e arbustos e algumas árvores podem ser arrancadas. Causa sérios danos em trailers, barcos ancorados e outdoors. Pequenos barcos em ancoradouros desprotegidos rompem suas amarras. Duas horas antes da chegada do olho do furacão diversos alagamentos podem ocorrer.

Categoria 3: Ventos entre 178 e 209 km/h. É um grande furacão. As ondas alcançam até 3,7 metros. Danos em estruturas de pequenas residências. Árvores de grande porte podem ser arrancadas. Trailers e outdoors são destruídos. Aproximadamente 3 horas antes da chegada do centro da tempestade locais de baixadas são alagados e áreas próximas à costa sofrem alagamentos, arrasando pequenas propriedades. Normalmente é requerida a evacuação das áreas mais baixas.

Categoria 4: Ventos entre 210 e $249 \mathrm{~km} / \mathrm{h}$. As ondas alcançam 5,5 metros. Destelhamento completo em pequenas residências. Árvores, arbustos e outdoors são arrancados. Destruição completa de trailers, grandes danos em portas e janelas. Aproximadamente 3 horas antes da chegada do olho do furacão locais de baixadas são alagados. Áreas 3 metros acima do nível médio do mar podem ser inundadas, requerendo massiva evacuação das áreas residências distantes até $10 \mathrm{~km}$ da costa.

Categoria 5: Ventos maiores que $249 \mathrm{~km} / \mathrm{h}$. Nível máximo da escala. As ondas ficam acima de 5,5 metros. Destelhamento total da maioria das casas e prédios industriais. Algumas casas são arrastadas com a força do vento. Todas as árvores, arbustos, outdoors e luminosos são arrancados e grandes danos nas áreas baixas localizadas a menos de 4,5 metros acima do nível médio do mar. Grandes inundações em uma distância de até 500 metros da linha da praia. Evacuação total nas áreas até $16 \mathrm{~km}$ da costa. (PARANÁ, 2015).

Em 12 de janeiro de 2010, ocorreu um devastador terremoto no Haiti. Em todos, além das inúmeras mortes, das pessoas gravemente feridas, houve milhares de deslocamentos forçados. Famílias foram devastadas. Ruas, prédios, escolas, casas, hospitais, fiações, redes de esgoto, documentos, procedimentos administrativos, processos judiciais que estavam em repartições e bairros foram destruídos. A economia, arrasada.

Conforme previamente abordado, além dos deslocamentos forçados em decorrência dos desastres naturais, é necessária a recordação das pessoas que saem de seus países por conta das condições climáticas. É o caso de muitos mexicanos. Segundo Lester Brown (2009): 
A cada dia, muitos mexicanos arriscam a vida no deserto do Arizona, tentando conseguir trabalho nos Estados Unidos. Em média, cerca de cem mil, ou mais, abandonam anualmente suas áreas rurais, onde aram terras muito pequenas ou muito afetadas pela erosão para que possam obter seu sustento. Dirigem-se a cidades mexicanas ou tentam cruzar ilegalmente a fronteira para os Estados Unidos. Muitos dos que tentam atravessar o deserto do Arizona morrem sob o sol abrasador. Desde 2001, a cada ano são encontrados, em média, 200 cadáveres ao longo da fronteira do Estado do Arizona.

A situação vivenciada pelos refugiados ambientais é dramática. Sebastião Salgado (2000, p. 7), se manifesta apresentando a sua percepção sobre o tema:

O livro conta a história da humanidade em trânsito. É uma história perturbadora, pois poucas pessoas abandonam a terra natal por vontade própria. Em geral elas se tornam migrantes, refugiadas ou exiladas constrangidas por forças que não têm como controlar, fugindo da pobreza, da depressão e das guerras. Partem com os pertences que conseguem carregar, avançar, a pé... Viajam sozinhas, com as famílias ou em grupos. Algumas sabem para onde estão indo, confiantes de que as espera uma vida melhor. Outras estão simplesmente em fuga, aliviadas por estarem vivas. Muitas não conseguirão chegar a lugar nenhum.

São alarmantes os dados apontados pela Organização das Nações Unidas. No relatório do Alto Comissariado das Nações Unidas para Refugiados em 23 de junho de 2014: "o deslocamento forçado no mundo" ultrapassa "50 milhões de pessoas". (ALTO COMISSARIADO DAS NAÇÕES UNIDAS PARA REFUGIADOS, 2014b). Um ponto fundamental para que esta situação seja contida é a proteção e a preservação ambiental. O cuidado com o meio ambiente, em âmbito nacional e internacional, é dever de todos: pessoas físicas, jurídicas e do Poder Público.

A Constituição Federal Brasileira de 1988, também conhecida como "Constituição-cidadã", prevê, no caput do art. 225 que:

"Todos têm direito ao meio ambiente ecologicamente equilibrado, bem de uso comum do povo e essencial à sadia qualidade de vida, impondo-se ao Poder Público e à coletividade o dever de defendê-lo e preservá-lo para as presentes e futuras gerações." (BRASIL, 1988).

Para tanto, é fundamental a conscientização sobre a relevância do equilíbrio entre as ações dos homens para os mais diversos fins (inclusive 
econômicos) e a proteção do meio ambiente. Neste sentido, Luís Paulo Sirvinskas leciona (2010, p. 63):

A importância da preservação dos recursos naturais passou a ser preocupação mundial e nenhum país pode eximir-se de sua responsabilidade. Tal necessidade de proteção do ambiente é antiga e surgiu quando o homem passou a valorizar a natureza, mas não de maneira tão acentuada como nos dias de hoje. Talvez não se desse muita importância à extinção dos animais e da flora, mas existia um respeito para com a natureza, por ser criação divina. Só depois que o homem começou a conhecer a interação dos microorganismos existentes no ecossistema é que sua responsabilidade aumentou.

A exploração predatória dos recursos tem como consequência a devastação ambiental, que traz graves sequelas para a fauna, a flora e os humanos, especialmente os moradores da área atingida. Além de medidas preventivas, como a proteção ambiental e a necessidade de redução da emissão de gases na atmosfera, são vitais os debates sobre a proteção das pessoas após a ocorrência destes desastres naturais, além dos impactos pela chegada destas pessoas nos novos países. Trata-se de um dos temas mais complexos da atualidade, um desafio global a ser debatido e estudado, na busca por soluções, sempre prestigiando o direito à vida e à dignidade humana.

\section{OS DIREITOS DOS REFUGIADOS E A NÃO ABRANGÊNCIA DOS REFUGIADOS AMBIENTAIS NAS CONVENÇÕES}

As migrações não são um fenômeno recente. José H. Fishel de Andrade (1996) esclarece que em passagens da Bíblia Sagrada estão os primeiros registros de deslocamentos. O artista Pieter Bruegel, o Velho, pintou, em 1566, a obra "The Census at Bethlehem" (o Censo de Belém). Esta obra retrata a chegada de José e Maria, ainda grávida, a Belém. Na paisagem, onde predomina o clima frio (com neve), é possível observar diversas pessoas se deslocando, para cumprirem as ordens do Imperador César Augusto, que, segundo o Evangelho de Lucas, determinava que todos os habitantes do Império fossem registrados (ou recenseados) no seu local de origem, para a contagem do primeiro censo.

O fenômeno das migrações, entretanto, foi agravado a partir da Revolução Industrial, em decorrência do desmatamento, da poluição e da transferência do campo para as cidades e a cada ano tem se ampliado mais. 
Uma das funções do Direito Internacional é a proteção dos direitos humanos, e é fundamental a integração das normas internacionais com as normas nacionais, além das constantes atualizações destes estudos (e a adequação destes às novas realidades), para a ampliação e a garantia dos direitos das pessoas. Entende Antônio Augusto Cançado Trindade (1997, p. 33) que:

No presente domínio de proteção, o direito internacional e o direito interno se mostram, assim, em constante interação. É a própria proteção internacional que requer medidas nacionais de implementação dos tratados de direitos humanos, assim como o fortalecimento das instituições nacionais vinculadas à vigência plena dos direitos humanos e do Estado de Direito. De tudo isto se pode depreender a premência da consolidação de obrigações erga omnes de proteção, consoante uma concepção necessariamente integral dos direitos humanos.

Deve, portanto, existir um núcleo de normas que compõem esta ramificação do Direito para tutelar e proteger os refugiados. As Organizações Internacionais também possuem vital importância para a proteção destas pessoas. Elas (as Organizações) já existem há muitos anos e, com o passar do tempo, foram sendo aperfeiçoadas para poderem cada vez mais trazer suporte aos necessitados. Tiago Schneider de Jesus (2009, p. 41-42) explica:

A Organização das Nações Unidas criou, em 3 de dezembro de 1949, o Alto Comissionado das Nações Unidas para os Refugiados - ACNUR, estruturando-o inicialmente como um órgão limitado e com poucos recursos, pelo fato de ter de submeter qualquer arrecadação de valores à aprovação da Assembléia Geral da ONU, refletindo diretamente o desejo dos EUA. Nesse sentido, apesar de suas funções primárias terem sido definidas com clareza, quais sejam, proporcionar proteção internacional aos refugiados e procurar soluções para os seus problemas, seu orçamento era bastante reduzido, não sendo suficiente para financiar tais objetivos. Essa situação mudou com a criação de um Fundo das Nações Unidas para os refugiados que, apesar de ainda não refletir os valores desejáveis, já permitia uma melhora significativa no atendimento às pessoas refugiadas.

Os refugiados também recebem auxílio e suporte da Organização Internacional para as Migrações (OIM), criada em 1951, e importante organização intergovernamental dedicada à área das migrações, que desenvolve diversas atividades dentre as quais: 
Assistir, assessorar e capacitar os Estados nos desafios que se impõem na gestão das migrações, avançar na compreensão das questões migratórias, promover o desenvolvimento social e econômico através da migração, garantir e velar pelo respeito da dignidade humana e o bem-estar dos migrantes, promover a cooperação internacional no âmbito das políticas migratórias. (ORGANIZAÇÃO INTERNACIONAL PARAAS MIGRAÇÕES, 2015).

Contam também com o apoio da Rede Solidária para Migrantes e Refugiados (2015):

A Rede Solidária para Migrantes e Refugiados é um espaço amplo de articulação, aberto tanto em âmbito nacional quanto internacional, em favor da causa dos migrantes e dos refugiados. A Rede não é, nem se propõe a ser uma nova entidade. Muitas instituições e organizações já existem e realizam, com esforço e dedicação, valiosa ação a serviço e em favor dos migrantes e dos refugiados e o propósito da Rede Solidária MIR é facilitar e favorecer os contatos, a articulação, o intercâmbio, a localização das entidades, na atuação junto e a favor dos migrantes e dos refugiados.

AAssembleia Geral da ONU, com a resolução de 55/76 de 2001, designou o dia 20 de junho para ser o Dia Mundial do Refugiado. Mas afinal, quem são as pessoas consideradas refugiadas? Segundo dados da Agência da Organização das Nações Unidas para Refugiados:

De acordo com a Convenção de 1951 relativa ao Estatuto dos Refugiados (de 1951), são refugiados as pessoas que se encontram fora do seu país por causa de fundado temor de perseguição por motivos de raça, religião, nacionalidade, opinião política ou participação em grupos sociais, e que não possa (ou não queira) voltar para casa. Posteriormente, definições mais amplas passaram a considerar como refugiados as pessoas obrigadas a deixar seu país devido a conflitos armados, violência generalizada e violação massiva dos direitos humanos. (ALTO COMISSARIADO DAS NAÇÕES UNIDAS PARAREFUGIADOS, 2014a).

Os refugiados saem de uma situação de intenso estresse em busca de novo local para poderem sobreviver e recomeçar suas vidas. $\mathrm{O}$ acolhimento destas pessoas deve imediatamente abranger bens materiais (muitas vezes oriundos de doações da população, como roupas, materiais para higiene pessoal, medicamentos), os tratamentos médico-hospitalares necessários, os cuidados 
com a hidratação e alimentação e o bem estar emocional, para que estas pessoas possam superar seus traumas e darem continuidade às suas atividades e à sua vida. (BRASIL, 2014).

Sobre a importância do acolhimento e a recuperação emocional:

Medo, desconfiança, tristeza, angústia, incerteza, dificuldade para dormir, irritabilidade, falta de concentração, falta ou excesso de apetite e crises de choro são reações normais nas pessoas atingidas por desastres. A expressão desses sentimentos ajuda na recuperação de quem passou por situações de perdas de entes queridos, patrimônios e abalo emocional devido à ocorrência de um desastre. (BRASIL, 2014).

O impacto emocional e suas consequências interferem na capacidade de adaptação e recuperação que habitualmente as pessoas têm frente a crises que ocorrem pelo curso da vida. Por isso, alguns cuidados são fundamentais para ajudar as pessoas atingidas por desastre a enfrentarem esse momento tão difícil. (BRASIL, 2014).

Algumas orientações para facilitar o convívio em ambiente coletivo:

- Desabafe com uma pessoa de sua confiança, conte o que sente e também escute os problemas dela. A solidariedade e apoio mútuo são formas de enfrentar o problema.

- Realize atividades com seus vizinhos para apoiarem-se mutuamente e superar os problemas gerados pelo desastre.

- Use somente medicamentos recomendados pelo médico. Não se automedique. Evite "tomar medicamentos para nervos" por conta própria.

- Não beba álcool ou outras drogas para driblar a situação ou para "sentir-se melhor".

- Use preservativos nas relações sexuais.

- Contribua nas atividades de limpeza e manutenção do abrigo, responsabilizando-se pelo bem-estar de todos.

- Promova a liderança positiva.

- Participe das tarefas que impliquem compromisso grupal e individual, por exemplo: cuidar de crianças menores; participar da preparação da alimentação etc.

- Forme grupos de conversa para possibilitar a expressão de seus sentimentos com a situação.

- Desencoraje condutas impensadas que conduzam a violência.

- Respeite o espaço do outro, mesmo vivendo em ambiente coletivo.

- Organize atividades esportivas e culturais. (BRASIL, 2014). 
Os funcionários dos abrigos devem zelar pela organização e limpeza do local, medidas fundamentais para que seja evitada a proliferação de doenças. O uso de panos limpos e de água sanitária é muito importante para a limpeza do ambiente.

Os direitos dos refugiados, de acordo com a Agência da Organização das Nações Unidas para Refugiados, são os seguintes: direito a asilo seguro, que abrange, além da segurança e integridade física, os mesmos direitos e mesmas assistências garantidas aos estrangeiros que legalmente residem no país (o que inclui a liberdade de pensamento, a liberdade de deslocamento e a não sujeição à tortura e a tratamentos degradantes).

Devem também ser garantidos os direitos econômicos e sociais. Todos devem ter acesso à assistência médica, deve ser garantido o direito de trabalho para os refugiados adultos e o acesso à escola para as crianças. É necessário refletir sobre a possibilidade de esgotamento dos bens e recursos utilizados para apoio aos refugiados, tendo em vista que a chegada de grande número de pessoas causa diversos impactos no país (nas finanças, na estrutura, distribuição de alimentos, medicamentos, utilização de água e energia, etc).

Nesta situação, é fundamental a cooperação entre os países e a atuação da Agência da Organização das Nações Unidas para Refugiados:

Quando não há mais recursos disponíveis dos países de acolhida, o ACNUR proporciona assistência aos refugiados (e outras pessoas sob seu mandato) que não possam satisfazer suas necessidades básicas. A assistência pode ser dada sob a forma de donativos financeiros, alimentação, materiais diversos (tais como utensílios de cozinha, ferramentas, sanitários e abrigos) ou de programas de criação de escolas ou centros de saúde para quem viva em campos ou outras comunidades. O ACNUR desenvolve todos os esforços para assegurar que os refugiados possam se tornar auto-suficientes o mais rápido possível, o que pode requerer atividades convencionais geradoras de rendas ou projetos de formação profissional. Os refugiados também têm determinadas obrigações, entre elas a de respeitar as leis do seu país de acolhida. (ALTO COMISSARIADO DAS NAÇÕES UNIDAS PARA REFUGIADOS, 2014a).

Existem diversos instrumentos internacionais voltados para a proteção dos refugiados: Declaração Universal dos Direitos Humanos (1948), Convenção das Nações Unidas sobre o estatuto dos Refugiados de 1951, Protocolo Relativo ao Estatuto dos Refugiados (1967), Conferência de Poznan da Polônia de 2008 
e a Lei $n^{\circ} .9474 / 97$, que regulamenta a aplicação do Estatuto do Refugiado no Brasil.

Érika Pires Ramos, entretanto, traz o seguinte alerta (2011, p. 9):

Dentro do debate sobre as mudanças climáticas, o tema das migrações ambientais surge como situação jurídica nova, não contemplada pelo Direito Internacional, uma vez que os chamados "refugiados ambientais" não se enquadram nas categorias tradicionais existentes, como é o caso do refugiado em sua acepção convencional, bem como não estão compreendidos nos demais grupos de migrantes reconhecidos em tratados e convenções internacionais vigentes.

As supracitadas legislações, portanto, apesar de terem enorme relevância para a proteção dos refugiados, perseguidos por motivos étnicos, religiosos, de raça, nacionalidade, grupo social ou opiniões políticas, não tutelam os refugiados ambientais.

O Programa das Nações Unidas para o Meio Ambiente (PNUMA) apresenta a seguinte definição para refugiado ambiental:

Refugiados ambientais são pessoas que foram obrigadas a abandonar temporária ou definitivamente a zona tradicional onde vivem, devido ao visível declínio do ambiente (por razões naturais ou humanas) perturbando a sua existência e/ou a qualidade da mesma de tal maneira que a subsistência dessas pessoas entra em perigo. Por declínio do ambiente se quer dizer, o surgir de uma transformação, tanto no campo físico, químico e/ou biológico do ecossistema que, por conseguinte, fará com que esse meio ambiente temporário ou permanentemente não possa ser utilizado. (PROGRAMA DAS NAÇÕES UNIDAS PARA O MEIO AMBIENTE, 1985).

Percebe-se que esta definição é muito mais ampla do que a Convenção de 1951. É necessária tutela legal que abranja esta situação para que os refugiados ambientais possuam direitos, possam reconstruir as suas vidas e exercer a cidadania.

\section{2015: CONFERÊNCIA DESTINADA À REDUÇÃO DAS ALTERAÇÕES CLIMÁTICAS}

No final do ano de 2015 (30 de novembro a 11 de dezembro de 2015) será realizada em Paris a COP 21 (United Nations Climate Change 
Conference), uma grande Conferência Internacional que tem por objetivo chegar a um acordo global sobre as mudanças climáticas, que deverá entrar em vigor em 2020, substituindo o Protocolo de Kyoto (acordo internacional criado na Convenção-Quadro das Nações Unidas sobre Mudanças Climáticas, que foi aprovado na cidade de Kyoto, no Japão, em 1997, tendo entrado em vigor em 16 de fevereiro de 2005, cujo principal objetivo é a estabilização da emissão de gases de efeito estufa na atmosfera para diminuir o aquecimento global).

Espera-se que discussões também tratem da situação dos refugiados ambientais. Nos dizeres de Érika Pires Ramos (2011, p. 9), ao discorrer sobre a importância destas pessoas terem status jurídico de refugiados ambientais:

Será necessário prever mecanismos institucionais que, de um lado, possam garantir efetiva proteção; de outro, possam prevenir, antecipar, financiar e organizar os movimentos populacionais dessa natureza, o que já há algum tempo sinaliza para uma crise humanitária sem precedentes. Assim como ocorreu com o regime internacional das mudanças climáticas, serão necessárias novas estratégias institucionais, novas formas de cooperação e de compromisso de longo prazo, uma vez que os mecanismos e instrumentos jurídicos internacionais existentes não são suficientes para atender a esta nova demanda global.

É fundamental a atualização das legislações internacionais para a adequação das tutelas protetivas às novas realidades. Para a defesa dos direitos humanos das pessoas que estão em estado crítico, Gésun Fernando Prestes (2013, p. 92) apresenta a seguinte sugestão:

A criação de um Estatuto próprio, aprimorando o conceito de refugiado ambiental, instituindo os direitos e deveres do beneficiado. Este estatuto deverá prover a segurança do refugiado, também, quanto aos seus direitos de cidadania adquiridos no país de origem, sendo esses mantidos até o retorno a ele, no mesmo sentido, com as expressões culturais, étnicas e costumes, pudessem ser garantidos a sua liberdade de expressão sem, contudo, ofender a cultura local.

É fundamental a adequação das Convenções Internacionais e das legislações internas aos novos desafios globais. A cooperação entre os Estados é vital para a proteção dos refugiados ambientais. 


\section{CONSIDERAÇÕES FINAIS}

O desenvolvimento das atividades humanas traz inúmeros benefícios para a Economia, a geração e manutenção de empregos. Entretanto, sem planejamento e redução dos impactos, acarreta também o desequilíbrio ambiental. Dentre as conseqüências extremas, as alterações climáticas e os fenômenos naturais catastróficos como os vendavais, terremotos e maremotos, bem como as permanentes alterações, que tornam inviável a vida no local. Os moradores da região atingida vivem situação dramática após o fenômeno e as dificuldades permanecem após o deslocamento para outros países. A falta de assistência médica, emocional, financeira e material são alguns dos desafios vivenciados pelos refugiados ambientais.

As Convenções Internacionais sobre os Refugiados não abarcam os refugiados ambientais, portanto não são suficientes para a proteção integral deles. $\mathrm{O}$ amparo às pessoas forçadas a se deslocarem abrange o direito à vida, à integridade física e mental. É uma necessidade premente que a sociedade internacional se debruce sobre o tema para encontrar as condições mais favoráveis para solucionar tão graves questões.

Espera-se a cooperação mútua entre os países bem como a adequação da proteção internacional ao novo contexto vivenciado na era globalizada, para a proteção da vida e da dignidade humana.

\section{REFERÊNCIAS}

ALTO COMISSARIADO DAS NAÇÕES UNIDAS PARA REFUGIADOS (ACNUR). Agência da ONU para Refugiados.

Disponível em: <http://www.acnur.org/.> . Acesso em: 14 dez. 2014a.

\section{Deslocamento forçado no mundo ultrapassa 50 milhões de}

pessoas. 2014b. Disponível em: <http://www.acnur.org/t3/portugues/noticias/ noticia/deslocamento-forcado-no-mundo-ultrapassa-50-milhoes-de-pessoas/ .>. Acesso em: 28 dez. 2014.

ANDRADE, José H. Fischel. Direito internacional dos refugiados: evolução histórica (1921-1952). Rio de Janeiro: Renovar, 1996. 
ARENDT, Hannah. Origens do totalitarismo. São Paulo: Companhia das Letras, 2009.

\section{BRASIL. Constituição da República Federativa do Brasil de 1988.}

Disponível em: <http://www.planalto.gov.br/ccivil_03/constituicao/ constituicao.htm>. Acesso em: 4 jan. 2015.

. Ministério da Saúde. Saiba como agir em caso de enchentes: abrigos. 2014. Disponível em: <http://bvsms.saude.gov.br/bvs/publicacoes/ saiba_agir_casos_abrigos_2014.pdf.>. Acesso em: 4 jan. 2015.

\section{. Ministério da Justiça. Declaração universal dos direitos}

humanos garante igualdade social. 2009. Disponível em: <http:// www.brasil.gov.br/cidadania-e-justica/2009/11/declaracao-universal-dosdireitos-humanos-garante-igualdade-social>. Acesso em: 4 jan. 2015.

. Observatório Nacional. Terra: conhecendo melhor o nosso planeta. Rio de Janeiro. 2. ed. 2011. Disponível em: <http://www.on.br/ pequeno_cientista/conteudo/revista/pdf/revista_terra.pdf.>. Acesso em: 2 jan. 2015.

BROWN, Lester. Mudança climática: aumenta a onda de refugiados ambientais. Washington. 2009. Disponível em: <http://www.ipsnoticias.net/ portuguese/2009/10/mundo/mudanca-climatica-aumenta-a-onda-derefugiados-ambientais/.>. Acesso em: 4 jan. 2015.

GORE JÚNIOR, Albert Arnold. A. Uma verdade inconveniente: o que você precisa saber (e fazer) sobre o aquecimento global. Tradução de Isa Mara Lando. Barueri: Manole, 2006.

JESUS, Tiago Schneider. Um novo desafio ao direito: deslocados/ imigrantes ambientais: reconhecimento, proteção e solidariedade. Dissertação (Mestrado em Direito) - Universidade de Caxias do Sul, Caxias do Sul, 2009.

LAFER, Celso. A reconstrução dos direitos humanos: a contribuição de Hannah Arendt. Estudos Avançados, São Paulo, v. 2, n. 30, p. 55-65, 1997. 
ORGANIZAÇÃO INTERNACIONAL PARA AS MIGRAÇÕES (OIM).

Disponível em: <http://www.campo.com.cv/>. Acesso em: 3 jan. 2015.

PARANÁ. Secretaria da Educação. Escala Saffir-Simpson. Disponível em: <http://www.geografia.seed.pr.gov.br/>. Acesso em: 2 jan. 2015.

PRESTES, Gésun Fernando. Refugiados ambientais à luz do direito ambiental internacional: o caso dos haitianos imigrantes no Brasil. Dissertação (Mestrado em Direito Ambiental e Desenvolvimento Sustentável) - Escola Superior Dom Helder Câmara, Belo Horizonte, 2013.

PROGRAMA DAS NAÇÕES UNIDAS PARA O MEIO AMBIENTE. Environmental refugees. Washington, DC, 1985.

RAMOS, Érika Pires. Refugiados ambientais: em busca de reconhecimento pelo direito internacional. Tese (Doutorado em Direito) Faculdade de Direito, Universidade de São Paulo, São Paulo, 2011.

REDE SOLIDÁRIA PARA MIGRANTES E REFUGIADOS. O que é a rede? Disponível em: <http://www.migrante.org.br/.>. Acesso em: 3 jan. 2015.

SALGADO, Sebastião. Êxodos. São Paulo: Companhia das Letras, 2000.

SARLET, Ingo Wolfgang. Dignidade da pessoa humana e direitos fundamentais na constituição federal de 1988. 7. ed. Porto Alegre: Livraria do Advogado, 2009.

SIRVINSKAS, Luís Paulo. Manual de direito ambiental. 8. ed. São Paulo: Saraiva, 2010.

SMANIO, Gianpaolo Poggio; BERTOLIN, Patrícia Tuma Martins. (Org.). O direito e as políticas públicas no Brasil. São Paulo: Atlas, 2013.

TRINDADE, Antônio Augusto Cançado. dilemas e desafios da proteção internacional dos direitos humanos no limiar do século XXI. Revista dos 
Estudantes de Direito da Universidade de Brasília, Brasília, p. 29-34, 1997. Disponível em: <http://periodicos.unb.br/index.php/redunb/article/ viewFile/3259/2849>. Acesso em: 4 jan. 2015.

Artigo enviado em: 06/01/2015 Aprovado para publicação em: 14/04/2015

Como citar: MACEDO, Maria Fernanda Soares. Alterações climáticas e o direito internacional dos refugiados: a busca pela dignidade humana e pela cidadania dos refugiados ambientais. Revista do Direito Público. Londrina, v.10, n.1, p.151-169, jan./abr.2015. DOI: 10.5433/1980511X.2015v10n1p151. 